\title{
FAKTOR-FAKTOR YANG MEMENGARUHI INTRA UTERIN FETAL DEATH (IUFD) PADA IBU BERSALIN DI RUMAH SAKIT UMUM DAERAH (RSUD) KOTA PADANGSIDIMPUAN TAHUN 2013
}

\author{
Setyawati Sulubara \\ Prodi Kebidanan Padangsidimpuan Poltekkes Medan
}

\begin{abstract}
Abstrak
Kematian maternal dan perinatal merupakan masalah besar. Menurut World Health Organization (WHO) tahun 2000 kematian perinatal 400/100.000 orang atau sekitar 200.000 ribu orang pertahun sehingga kematian perinatal terjadi 1.2-1.5 menit. Tujuan penelitian ini adalah untuk mengetahui jumlah kasus IUFD di RSUD Kota Padangsidimpuan tahun 2013. Jenis penelitian ini adalah penelitian secara deskriptif yaitu untuk mengetahui faktor-faktor yang memengaruhi IUFD pada ibu bersalin di RSUD Kota Padangsidimpuan tahun 2013, dengan menggunakan data sekunder dari Medical Record. Populasi dalam penelitian ini adalah seluruh ibu bersalin di RSUD Kota Padangsidimpuan tahun 2013 yang berjumlah 27 orang. Data sekunder yang dikumpulkan dari catatan rekam medik (medical record) IUFD di RSUD Kota Padangsidimpuan tahun 2013. Data kemudian dianalisis secara deskriptif dengan melihat angka yang telah dikumpul pada setiap karakteristik variabel dan disajikan dalam tabel distribusi frekuensi, kemudian dilanjutkan dengan membahas hasil denhan menggunakan teori yang ada. Berdasarkan frekuensi kejadian IUFD berjumlah 27 dari 1510 persalinan. Berdasarkan faktor komplikasi penyakit ibu lebih banyak terjadi pada pre-eklampsia dan eklampsia berjumlah 14 kasus $(51.8 \%)$, berdasarkan faktor plasenta lebih banyak pada kasus plasenta previa 15 kasus $(55.5 \%)$, berdasarkan faktor resiko pada kasus usia ibu lebih banyak pada usia 25-35 tahun berjumlah 15 kasus (55.5\%), berdasarkan usia kehamilan > 28 minggu berjumlah 18 kasus $(66.7 \%)$. Melihat angka kejadian IUFD yang tinggi perlu mendapatkan penanganan yang intensif dengan melakukan pemeriksaan minimal 4 kali kehamilan, mengikuti program KB dan mengatur jarak kehamilan.
\end{abstract}

Kata Kunci: IUFD, Ibu Bersalin

\section{PENDAHULUAN}

Kematian maternal dan perinatal merupakan masalah besar, khususnya di negara berkembang sekitar $98 \%-99 \%$, sedangkan negara maju hanya $1 \%$ 2\%. Menurut laporan World Health Organization (WHO) tahun 2000 kematian perinatal adalah 400 per 100.000 orang atau sekitar 200.000 ribu orang pertahun sehingga kematian perinatal 1.2-1.5 menit. Kematian perinatal di Indonesia adalah yang tertinggi diantara negara-negara Association South of East Nation (ASEAN) kejadiannya sekitar 15 kali di Malaysia (Manuaba, 2007).

Sekitar 50\% kematian perinatal merupakan kelahiran mati. Dari semua kematian janin di Amerika Serikat, lebih dari dua pertiga terjadi sebelum 32 minggu kehamilan, 22\% terjadi antara 36 dan 40 minggu kehamilan, dan sekitar $10 \%$ terjadi diluar kehamilan 41 minggu.

Dibandingkan dengan negara-negara maju dan beberapa negara Aisa angka kematian perinatal di negara kita masih tinggi yaitu berkisar antara 77.5-142.2 per 1000 kelahiran (Sinopsis Obstetri).
Angka kematian perinatal (AKP) di Indonesia belum diketahui pasti karena belum ada penelitian menyeluruh mengenai hal ini. Diperkirakan AKP di rumah sakit berkisar antara 77.3 sampai 137.7 per 1000 kelahiran hidup.

Berdasarkan data dari kementerian kesehatan pada 2011 lalu Indonesia menyandang predikat pertama kasus kematian ibu dan janin di Asia. Tahun 2011 angka itu 228 per 100.000 ibu melahirkan dan 35 per 100.000 kelahiran anak.

Berdasarkan survey awal yang dilakukan peneliti di RSUD KOta Padangsidimpuan tahun 2013 ditemukan 27 persalinan dengan intra uteri fetal death diantara 1510 persalinan.

Berdasarkan visi Prodi Kebidanan Padangsidimpuan dimana asuhan kebidanan unggul dalam penanganan kegawatdaruratan kebidanan mandiri di wilayah Sumatera Utara tahun 2018.

Berdasarkan uruaian diatas, maka peneliti tertarik melakukan penelitian lanjut faktor-faktor yang memengaruhi IUFD di kota Padangsidimpuan tahun 2013. 


\section{METODE PENELITIAN}

Jenis penelitian ini adalah penelitian secara deskriptif yaitu untuk mengetahui faktor-faktor yang memengaruhi IUFD pada ibu bersalin di RSUD Kota Padangsidimpuan tahun 2013, dengan menggunakan data sekunder dari Medical Record. Populasi dalam penelitian ini adalah seluruh ibu bersalin di RSUD Kota Padangsidimpuan tahun 2013 yang berjumlah 27 orang. Data sekunder yang dikumpulkan dari catatan rekam medik (medical record) IUFD di RSUD Kota Padangsidimpuan tahun 2013. Data kemudian dianalisis secara deskriptif dengan melihat angka yang telah dikumpul pada setiap karakteristik variabel dan disajikan dalam tabel distribusi frekuensi, kemudian dilanjutkan dengan membahas hasil denhan menggunakan teori yang ada.

\section{HASIL PENELITIAN DAN PEMBAHASAN}

\section{Distribusi Frekuensi IUFD di RSUD \\ Kota Padangsidimpuan}

Kasus IUFD di RSUD Kota Padangsidimpuan adalah 27 kasus yaitu $1.8 \%$ dari keseluruhan jumlah persalianan yang terjadi selama tahun 2013.

2. Faktor yang memengaruhi IUFD di RSUD Kota Padangsidimpuan

\subsection{Faktor Komplikasi Penyakit Ibu}

Tabel 1. Distribusi frekuensi IUFD berdasarkan faktor komplikasi penyakit Ibu di RSUD Kota Padangsidimpuan

\begin{tabular}{|c|c|c|c|}
\hline No & Faktor Ibu & Jumlah & \% \\
\hline 1. & $\begin{array}{c}\text { Pre-eklampsia dan } \\
\text { Eklampsia }\end{array}$ & 14 & $51.8 \%$ \\
\hline 2. & Infeksi & 7 & $26 \%$ \\
\hline 3. & $\begin{array}{c}\text { Tanpa komplikasi } \\
\text { penyakit }\end{array}$ & 6 & $22.2 \%$ \\
\hline \multicolumn{2}{|c|}{ Jumlah } & 27 & $100 \%$ \\
\hline
\end{tabular}

Dari tabel 1 diatas diketahui bahwa jumlah kasus IUFD berdasarkan faktor ibu mayoritas disebabkan oleh pre-eklampsia dan eklampsia yaitu sebanyak 10 kasus $(37.0 \%)$ dan minoritas disebabkan oleh tanpa komplikasi penyakit yaitu 6 kasus $(22.2 \%)$.

\subsection{Faktor Plasenta}

Tabel 2. Distribusi frekuensi IUFD berdasarkan faktor plasenta di RSUD Kota Padangsidimpuan

\begin{tabular}{|c|c|c|c|}
\hline No & Faktor Plasenta & Jumlah & \% \\
\hline 1. & Solusio Plasenta & 10 & $37.0 \%$ \\
\hline 2. & Plasenta Previa & 15 & $55.5 \%$ \\
\hline 3. & Plasenta Normal & 2 & $7.5 \%$ \\
\hline \multicolumn{2}{|c|}{ Jumlah } & 27 & $100 \%$ \\
\hline
\end{tabular}

Dari tabel 2 diatas diketahui bahwa jumlah kasus IUFD berdasarkan faktor plasenta mayoritas disebabkan oleh plasenta previa yaitu sebanyak 15 kasus $(55.5 \%)$ dan minoritas disebabkan oleh plasenta normal yaitu 2 kasus (7.5\%).

\subsection{Faktor Usia}

Tabel 3. Distribusi frekuensi IUFD berdasarkan faktor usia di RSUD Kota Padangsidimpuan

\begin{tabular}{|c|c|c|c|}
\hline No & Usia & Jumlah & \% \\
\hline 1. & $<20$ tahun & 1 & $3.7 \%$ \\
\hline 2. & $25-35$ tahun & 19 & $70.3 \%$ \\
\hline 3. & $>35$ tahun & 7 & $26 \%$ \\
\hline \multicolumn{2}{|c|}{ Jumlah } & 27 & $100 \%$ \\
\hline
\end{tabular}

Dari tabel 3 diatas diketahui bahwa jumlah kasus IUFD berdasarkan faktor usia mayoritas berusia 20-35 tahun yaitu sebanyak 19 kasus $(70.3 \%)$ dan minoritas berusia $<25$ tahun yaitu 1 kasus $(3.7 \%)$.

\subsection{Faktor Paritas Ibu}

Tabel 4. Distribusi frekuensi IUFD berdasarkan faktor Paritas Ibu di RSUD Kota Padangsidimpuan

\begin{tabular}{|c|c|c|c|}
\hline No & Paritas & Jumlah & \% \\
\hline 1. & Primipara & 15 & $55.5 \%$ \\
\hline 2. & Multipara & 7 & $26 \%$ \\
\hline 3. & Grandemultipara & 5 & $18.5 \%$ \\
\hline \multicolumn{2}{|l}{ Jumlah } & 27 & $100 \%$ \\
\hline
\end{tabular}

Dari tabel 3 diatas diketahui bahwa jumlah kasus IUFD berdasarkan faktor paritas ibu mayoritas primipara yaitu sebanyak 19 kasus (70.3\%) dan minoritas memiliki paritas grandemultipara yaitu 5 kasus $(18.5 \%)$.

\subsection{Faktor Usia Kehamilan Ibu}

Tabel 5. Distribusi frekuensi IUFD berdasarkan Usia Kehamilan Ibu di RSUD Kota Padangsidimpuan

\begin{tabular}{|c|c|c|c|}
\hline No & Usia Kehamilan & Jumlah & \% \\
\hline 1. & $<28$ minggu & 9 & $33.3 \%$ \\
\hline 2. & $>28$ minggu & 18 & $66.7 \%$ \\
\hline \multicolumn{2}{|c|}{ Jumlah } & 27 & $100 \%$ \\
\hline
\end{tabular}

Dari tabel 3 diatas diketahui bahwa jumlah kasus IUFD berdasarkan usia kehamilan ibu mayoritas terjadi pada usia kehamilan $>28$ minggu yaitu sebanyak 18 kasus $(66.7 \%)$ dan minoritas memiliki pada usia kehamilan $<28$ minggu yaitu 9 kasus $(33.3 \%)$.

\section{PEMBAHASAN}

\subsection{Faktor Komplikasi Penyakit Ibu}

Berdasarkan hasil penelitian dapat dilihat bahwa jumlah kasus IUFD ditemukan mayoritas terjadi pada kasus pre-eklmapsia dan eklampsia yaitu sebanyak 14 kasus $(51.8 \%)$.

Pre-eklampsia dan eklampsia merupakan kumpulan gejala yang timbul pada ibu hamil, bersalin dan nifas yang terdiri dari trias klasik yaitu hipetensi, proteinuria dan oedema kadang-kadang disertai konvulsi sampai koma.

Gejala awal pre-eklampsia menyebabkan terjadinya kerusakan endotel, insudasi dari plasma ke dinding pembuluh darah, profilerasi sel miointimal dan nekrosis medial. Lipid dapat terkumpul pada sel-sel mioinmital dan didalam mikrofag. Akibat dari gangguan pembuluh darah tersebut, terjadi peningkata tekanan darah serta kurangnya pasokan oksigen dan nutrisi ke plasenta. Kondisi iskemia 
tersebut membuat plasenta mengeluarkan faktor-faktor tertentu yang dapat memicu inflamasi secara sistemik. Dengan begitu maka asupan gizi pada janin akan mengalami kelainan sehingga janin akan mulai stress dslam kandungan atau sampai kematian dalam kandungan.

\subsection{Faktor Plasenta}

Berdasarkan hasil penelitian yang dilakukan bahwa kasus IUFD mayoritas disebabkan oleh plasenta previa yaitu sebanyak 15 kasus (55.5\%).

Plasenta previa adalah keadaan dimana plasenta berimplantasi pada tempat secara abnormal, yaitu pada segmen bawah rahim sehingga menutupi sebagian atau seluruh pembukaan jalan lahir. Apabila plasenta tumbuh pada SBR dan pembukaan serviks tidak dapt diikuti oleh plasenta yang melekat disitu tanpa terlepasnya sebagian plasenta dari dinding uterus. Pada saat ini mulailah terjadi perdarahan dan menyebabkan anemia karena tertekannya plasenta menyebabkan keluarnya darah dari jalan lahir, dimana asupan darah ke janin akan otomatis berkurang atau bahkan terputus sehingga menyebabkan keadaan bayi lahir prematur, asphiksia berat dan bahkan kematian janin.

\subsection{Faktor Usia}

Berdasarkan hasil penelitian yang telah dilakukan dapat dilihat bahwa mayoritas kejadian IUFd terjadi pada ibu yang berusia 20-35 tahun yaitu sebanyak 19 kasus $(70.3 \%)$.

Usia memiliki pengaruh terhadap kehamilan dan persalinan ibu. Resiko tinggi kelahiran mati terjadi pada ibu yang berumur $<20$ tahun dan $>35$ tahun. Banyak ibu yang berusia $<20$ tahun belum cukup matang dalam menghadapi kehamilan dan persalinan. Pada usia $<20$ tahun, rahim dan panggul ibu belum berkembang dengan baik, sehingga perlu diwaspadai kemungkinan mengalami gangguan persalinan yang sulit dan keracunan kehamilan atau gangguan lain karena ketidaksiapan ibu untuk menerima tugas dan tanggung jawabnya sebagai orangtua. Sebaliknya jika terjadi kehamilan pada usia >35 tahun, tubuh ibu sudah kurang siap lagi menghadapi kehamilan dan persalinan. Ibu yang berusia $>35$ tahun cenderung mengalami perdarahan, hipertensi, diabetes, obesitas, myoma uteri, persalinan lama dan penyakit lainnya.

Hasil penelitian ini tidak signifikan dengan teori, yang mana ibu yang berusia 20-35 lebih dominan mengalami IUFD ketimbang ibu yang berusia $<20$ tahun dan $>35$ tahun. Ini disebabkan karena tingkat pengetahuan dan tingkat kesadaran ibu semakin baik terhadap kehamilan di usia muda dan tua sehingga kebanyakan kehamilan ibu terjadi di usia 25-35 tahun.

\subsection{Paritas}

Dari penelitian ini didapatkan hasil bahwa jumlah kasus IUFD, mayoritas terjadi pada primipara yaitu sebanyak 19 kasus (70.3\%).

Resiko terhadap kesehatan ibu dan anak meningkat pada persalinan pertama, keempat dan seterusnya. Kehamilan yang paling aman adalah kehamilan kedua dan ketiga. Hal ini sesuai dengan pendapat Moeluk tahun 1983 yang dikutip oleh Sarumpaet (2000), yang menyatakan bahwa persalinan yang paling aman adalah persalinan kedua dan ketiga. Kehamilan dan persalinan pertama memiliki resiko karena pengalaman pertama dan rahim ibu mengalami peregangan dan penegangan sehingga kemungkinan akan mengalami gangguan pada hamil, melahirkan dan nifas apalagi ditambah dengan kekurangan gizi sebelum dan selama kehamilan.

\subsection{Usia Kehamilan}

Dari hasil penelitian didapatkan hasil bahwa jumlah kasus IUFD terjadi pada usia kehamilan $>28$ minggu yaitu sebanyak 18 kasus $(66.7 \%)$.

Sanusi P (1994) menyatakan bahwa usia kehamilan memiliki korelasi yang erat dengan angka kematian perinatal, makin rendah atau makin tinggi masa gestasi maka makin besar resiko terjadinya IUFD. Kehamilan trimester III adalah kehamilan pada usia 29-42 minggu. Deteksi dini gejala dan tanda bahaya selama kehamilan merupakan upaya terbaik untuk mencegah terjadinya gangguan yang serius terhadap kehamilan atau keselamatan ibu hamil.

Banyaknya kematian pada usia kehamilan trimester ketiga dipengaruhi karena tingkat pengawasan ibu terhadap kehamilan semakin berkurang, sehingga komplikasi yang mungkin muncul pada usia kehamilan tersebut tidak diawasi sehingga menyebabkan kondisi kehidupan janin yang memburuk dan bahkan kematian.

\section{KESIMPULAN DAN SARAN}

\section{Kesimpulan}

Berdasarkan hasil penelitian mengenai factorfaktor yang memengaruhi IUFD pada ibu bersalin di RSUD Kota Padangsidimpuan Tahun 2013 dapat disimpulkan bahwa :

1. Jumlah kasus IUFD di RSUD Kota padangsidimpuan tahun 2013 adalah 27 kasus (1.8\%0 dari 1510 persalinan.

2. Mayoritas kasus IUFD disebabkan oleh kejadian pre-eklampsia dan eklampsia yaitu sebanyak 14 kasus $(51.8 \%)$.

3. Mayoritas kasus IUFD terjadi karena letak plasenta previa yaitu sebanyak 15 kasus $(55.5 \%)$.

4. Mayoritas kasus IUFD terjadi pada usia 25-35 tahun yaitu sebanyak 19 kasus (70.3\%).

5. Mayoritas kasus IUFD terjadi pada primipara yaitu sebanyak 15 kasus (55.5\%).

6. Mayoritas kasus IUFD terjadi pada usia kehamilan <28 minggu yaitu sebanyak 18 kasus $(66.7 \%)$.

\section{Saran}

1. Dianjurkan kepada setiap ibu hamil agar selalu rutin melakukan kunjungan antenatal care (ANC) kepada bidan atau tenaga kesehatan minimal 4 kali selama 9 bulan, memakai KB dan mengatur jarak kehamilan.

2. Bagi tenaga kesehatan agar lebih meningkatkan pelayanan kesehatan khususnya asuhan pada ibu hamil dengan memberikan penyuluhan atau 
konseling kepada pasangan usia subur (PUS) dan wanita usia subur (WUS) serta memiliki kemampuan dan ilmu pengetahuan yang professional agar dapat menurunkan angka kematian perinatal.

3. Diharapkan kepada pendidikan untuk selalu meningkatkan kualitas dan kuantitas ilmu pengetahuan sehingga dapat menghasilkan lulusan kebidanan yang professional, mampu menangani tuntutan kesehatan dan tanggap dalam penanganan kegawatdaruratan.

\section{DAFTAR PUSTAKA}

Disni Surya Ningsih, 2014. Kematian Janin dalam Rahim, diakses 27 April 2014.

Gita Kostania. 2014, Kematian Janin dalam Rahim, diakses 07 April 2014.

Gunandar Azikin, Gambaran Faktor yang Berpengaruh terhadap Kematian Janin dalam Rahim.

Marni, Retno, dkk, 2011; Asuhan Kebidanan Patologi, Yogyakarta : Pustaka Pelajar.

Mayunani, Anik, dkk. 2013; Asuhan Kegawatdaruratan Maternal dan Neonatal. Jakarta:TIM.
Mochtar, R. 1988 ; Sinopsis Obstetri Jilid I edisi ke-2. Jakarta;EGC.

Nugroho, DR.Taufan, 2001. Buku Ajar Obstetri. Yogyakarta:Nuha Medica.

Nurs Dina, 2011. Intra Uterin fetal Death, diakses 24 April 2014.

Oxom, Harry, dkk. 2010: Ilmu Kebidanan edisi 2. Yogyakarta:Yayasan Essentia Medica.

Prawirohardjo, Sarwono. 2009. Ilmu Kebidanan Edisi 4. Jakarta: Yayasan Bina Pustaka.

Reka, 2014. IUFD, diakses 1 Mei 2014

Sujiyatini, M.Keb, dkk. 2009. Asuhan patologi Kebidanan Edisi 1. Yogyakarta : Nuha Medica.

Trijatmo, dkk. 2010. Ilmu Kebidanan, Jakarta: Prakata.

Ummi Rosmalasari, 2012. Kematian Perinatal, diakses 15 April 2014.

Viktor, 2008. Analisis Faktor Resiko pada Kelahiran Mati di Kabupaten Tapanuli Utara tahun 2005-2006, diakses 17 April 2014. 